\title{
LAW, INCOMMENSURABILITY, AND EXPRESSION
}

\section{STEPHEN GARDBAUM $\dagger$}

One of the great merits of this Symposium has been to identify and clarify the important distinction between the concepts of incommensurability and incomparability. Broadly speaking, the distinction reflects that between cardinal and ordinal rankings. ${ }^{1}$ That is, if two options are incommensurable, they cannot precisely be measured and ranked against each other by a single scale of value. However, incommensurability does not entail that the two options cannot be compared at all, or ranked as better or worse than the other. Incomparability, conversely, means that even this latter ordinal ranking is impossible. As the various contributions amply have illustrated, this distinction, and the general subject of incommensurability that can be said to include both concepts, have important implications for moral reasoning, practical reasoning, and public policy.

The general issue also has important implications for political reasoning, for if the incommensurability of competing ways of life does not prevent their comparability and ordinal ranking, so that one can nonetheless be said to be better than another, this would be a conclusion of some significance in contemporary debates concerning the nature and justification of liberal theory. It would, for example, bolster the claims of political perfectionism, the general structure of which is that if one way of life is better than others, the state has reason to promote it. ${ }^{2}$ By contrast, the incomparability of ways of life might supplement the argument for the more impartial stance on the part of the state that has come to be known as "political liberalism.",

† Professor of Law, Northwestern University School of Law; Visiting Professor of Law, University of Arizona College of Law.

In her oral presentation, Ruth Chang expressed a particularly clear statement of this distinction. For further discussion, see Ruth Chang, Introduction, in INCOMMENSURABILITY, INCOMPARABILITY, AND PRACTICAL REASON 1, 1-4 (Ruth Chang ed., 1997).

${ }^{2}$ For Joseph Raz, "perfectionist doctrine ... holds the state to be duty-bound to promote the good life." JOSEPH RAZ, THE MORALITY OF FREEDOM 426 (1986).

${ }^{3}$ Proponents of political liberalism generally do not rely on incomparability, but rather on the fact of reasonable disagreement among citizens concerning different ways of life, which they contend renders a partisan stance on the part of the state unjustified. See Charles Larmore, Political Liberalism, 18 POL. THEORY 339, 340 (1990) 
In addition to the concepts of incommensurability and incomparability, there is a third important concept that is sometimes confused with these two, particularly in the context of political theory where it has been employed influentially. This third concept is the incompatibility of values, and it was famously relied upon by Isaiah Berlin in his critique of monistic political thought. ${ }^{4}$ The concept of value incompatibility underlies that of value pluralism in that it is the incompatibility of different values that accounts for their irreducibility and distinctiveness. Incompatibility, however, is not the same as either incommensurability or incomparability, because to claim that values are irreducibly plural is not itself to claim anything about whether or how they can be measured, compared, or ranked. Thus, to assert, for example, that liberty is distinct from, and cannot be reduced to, equality is not to assert that liberty cannot be more important or valuable than equality (as Berlin seems ultimately to have believed), ${ }^{5}$ but rather that we cannot have everything. More generally, value incompatibility and pluralism does not imply that there can be no justified choice between options expressing those values; it means that even if there is a justified choice, some moral loss will still inevitably be involved. By contrast, incommensurability and incomparability directly raise the issue of the possibility of justified choice. Value pluralism by itself, then, is not inconsistent with perfectionism; indeed, on some accounts it is a necessary condition of it. ${ }^{6}$

The incomparability of values would appear to provide a number of additional reasons beyond value pluralism for such a characteristic liberal practice as expressive freedom. Thus, if forms or ways of life are incomparable and not merely incompatible, so that their relative worth cannot be evaluated, this would seem to call into question a

("[W] hether the different forms of the good can be ranked, and if so how, is one of the items about which reasonable disagreement tends to thrive."). Whether the fact of incomparability, which would make such disagreement no longer reasonable, would radically change the claims of political liberalism is an interesting issue.

${ }^{1}$ See ISAIAH BERLIN, TWO CONCEPTS OF LIBERTY 54 (1958) ("[T] he belief that some single formula can in principle be found whereby all the diverse ends of men can be harmoniously realized is demonstrably false. If, as I believe, the ends of men are many, and not all of them are in principle compatible with each other, then the possibility of conflict-and of tragedy-can never wholly be eliminated from human life, either personal or social. The necessity of choosing between absolute claims is then an inescapable characteristic of the human condition.").

${ }^{5}$ See id. at 55 ("[L] iberty to choose ... must be weighed against the claims of many other values .... For this reason, it cannot be unlimited.").

${ }^{6}$ See RAZ, supra note 2, at 398 (arguing that the perfectionist ideal of personal autonomy requires value pluralism). 
number of traditional justifications for entrusting the choice among them to a social, political, religious, or intellectual elite rather than to the citizenry as a whole. Robust freedom of expression then might be viewed as necessary for promoting informed and deliberative collective self-government. Moreover, apart from this issue of who does the choosing, the incomparability of values should lead to greater importance being attached to the act of choice itself-and its preconditions-absent the external "coercive" force of compelling reasons. Again, in this context, robust freedom of expression might be understood as critical for promoting autonomy and the capacity to exercise choice. $^{7}$ On the other hand, incomparability arguably undermines one traditional argument for freedom of expression-that it is the means to truth-since no amount of discussion will render two incomparable options comparable.

Although the two excellent articles upon which I am commenting do not address the implications of incommensurability for political reasoning, but rather address its implications for contractual and moral reasoning, they both raise the connection between incommensurability and expressive conduct more generally. In An Expressive Theory of Contract, Professor Gillian Hadfield argues that value pluralism and incommensurability compel recognition of the expressive dimension of contractual choice. ${ }^{8}$ By contrast, in Incommensurable Goods, Rightful Lies, and the Wrongness of Fraud, Professor Alan Strudler argues that there is no necessary link between incommensurability and expressive concerns, and that in practice such a link is far more the exception than the rule.

\section{I}

In her important and provocative article, Professor Hadfield presents a reconceptualization of the source of contractual obligation

${ }^{7}$ The instrumental connection between freedom of expression and autonomy should not be understood as ruling out the possibility that this latter value is best promoted by focusing primarily on the autonomy of hearers rather than speakers. See Stephen A. Gardbaum, Broadcasting, Democracy, and the Market, 82 GEO. L.J. 373, 380-82 (1993) (offering several justifications for granting priority to the autonomy of hearers rather than speakers).

${ }^{B}$ See Gillian K. Hadfield, An Expressive Theory of Contract: From Feminist Dilemmas to a Reconceptualization of Rational Choice in Contract Law, 146 U. PA. L. REV. 1235, 1261-63 (1998).

See Alan Strudler, Incommensurable Goods, Rightful Lies, and the Wrongness of Fraud, 146 U. PA. L. REV. 1529, 1564-66 (1998) (refuting the existence of "a general connection between self-expression and incommensurables"). 
that, she argues, provides a solution to the feminist dilemma of choice: namely, how to protect women from the oppressive consequences of harmful, constrained choices without thereby divesting them of full and equal contractual agency. ${ }^{10}$ Her vehicle in this enterprise is a conception of choice in contract law that takes into account the plurality and incommensurability of value and provides an alternative to the dominant rational choice model.

Drawing on the concept of expressive rationality developed by the philosopher Elizabeth Anderson, "Hadfield argues that contrary to the conventional doctrine, which squeezes diverse forms into the straitjacket of a single model, there are at least two types or categories of contracts. These are, first, those that typically are entered into in a risk-allocation frame of mind, based on the party's weighing of the expected costs and benefits of contracting; and, second, those that are entered into for expressive rather than such instrumental reasons. ${ }^{12}$ Hadfield illustrates this distinction by reference to three particular examples of expressive contracts which raise the feminist dilemma in stark terms: surrogacy contracts, marital separation agreements, and a wife's guarantee of her husband's business debts. ${ }^{13}$ The major implication of this distinction, according to Hadfield, is that what she characterizes as the standard logic and justification of contract enforcement-the mere fact that "she chose"-does not apply in the case of expressive contracts, as the promisor did not in fact choose to assume a risk about the future; this is not what she understood herself to be doing when she entered the contact. ${ }^{14}$

This is an extremely interesting argument, and I have two initial comments on it. First, particularly once one attempts to generalize away from the three particular types of expressive contracts discussed in the article, as Hadfield does in her conclusion, it strikes me that more needs to be said about the division between the two categories

${ }^{10}$ See Hadfield, supra note 8, at 1248. Hadfield expresses the dilemma as follows: Under current law, "[w] hen a woman seeks release from a harmful contract, she argues that she is exceptionally diminished in her capacity to assume responsibility for her choices." Id.

"See Elizabeth ANderson, Value in Ethics AND ECONOMics $17-43$ (1993) (presenting an expressive theory of rational action); Richard H. Pildes \& Elizabeth S. Anderson, Slinging Arrows at Democracy: Social Choice Theory, Value Pluralism, and Democratic Politics, 90 COLUM. L. REV. 2121, 2127 (1990) (offering an alternative, expressive conception of the structure of rationality to social choice theory that the authors claim "rests on peculiar conceptions of rationality and of democratic politics").

12 See Hadfield, supra note 8, at 1261-63.

is See id. at 1263-76.

${ }^{14}$ See id. at 1281-82. 
of contracts. This is because there often may be a difference between the reasons for which one enters a contract and what the promisor understands herself to be doing in entering it. The "frame of mind" in which one enters the contract plausibly may be said to encompass both. So, for example, a friend may lend me money or invest capital in a business idea of mine in order to express her sense of our friendship, while still thinking of it as a business transaction in the sense of expecting to be repaid or rewarded. Does she enter this contract in a risk-allocation frame of mind or an expressive one? Or take the example of a fully informed and contractually sophisticated spouse who nonetheless enters into a guarantee to express faith in her marriage and/or her partner's business acumen. Such examples suggest that the division between expressive and instrumental modes of entering a contract may not always or typically be alternatives, but instead may reflect different dimensions that are both present in a given contract: the motivating reason for creating the obligation, and the practical consequences one understands and expects to follow from it. Where both dimensions are present, I think the argument-that the normal contract rationale for enforcement does not apply-is incomplete. Perhaps it is necessary to determine which is the dominant frame of mind. On the other hand, if only purely instrumental contractsthose in which no expressive element is present at all-are subject to the normal rule, this would constitute a far more radical reconstruction of contract law than Hadfield appears to contemplate or desire in her article. Many commercial contracts, including (but not limited to) relational ones, ${ }^{15}$ have some expressive dimension.

Second, in drawing her distinction, Hadfield equates expressive choice with present-orientation and instrumental choice with futureorientation. It is because expressive choice is linked to the present rather than the future that the "you chose" justification for contract enforcement does not work in the case of expressive contracts. ${ }^{16} \mathrm{I}$ am a little unsure, however, about the validity-or, indeed, the necessity-of this equation and thus the consequent critique of the standard enforcement rationale. It seems to me that expressive choice

${ }^{15}$ On relational contracts generally, see IAN MACNEIL, THE NEW SOCIAL CONTRACT (1980).

${ }^{16}$ See Hadfield, supra note 8, at 1262 ("If the reason for pointing at the goods in the window was present-oriented and not made with a view to choosing a desired future-if the promise-making was expressive and not instrumental-what is the rationale for requiring a state of affairs to follow if, when the future comes, our chooser now says she does not wish to choose accordingly?"). 
may be (and often is) future-oriented, even if not oriented to future risk allocation. This is because part of the expressive force of a person's entry into a contract may stem from the fact that she is binding herself for the future and will be held to her promise. Being bound may be an essential part of what she is expressing, and thus may represent a different expressive choice than merely a present intention to do something in the future-or a choice without any reference to the future. So, for example, an intrinsic part of the expressive choice made in a separation agreement may be being bound by it in the future. Such a choice perhaps expresses more independence from the former spouse than one that is purely present-oriented. In the case of the guarantee of business debts, choosing to enter into a contract in which the house is knowingly at stake may express more trust in the marriage than one in which the house is not at stake. Where being bound in the future is an essential part of what a person is expressing when entering into a contract, there may then be a reason to enforce the contract in the normal way: This is part of the expressive choice the person made. She chose to bind herself in the future even if for expressive and not risk-allocation reasons-that is, for reasons other than that the expected benefits outweigh the expected costs.

Indeed, in her conclusion, Hadfield suggests how the analysis of relational contracts and their enforcement is enhanced by the expressive theory of choice. ${ }^{17}$ Yet relational contracts are, of course, even more future-oriented than traditional, discrete ones.

In terms of the reconstruction of contract law that acknowledging the expressive nature of much contract formation involves, Hadfield argues that there are two better reasons for enforcement of expressive contracts than the traditional "she chose" reason: namely, the reliance interest and institutional policy. ${ }^{18}$ Moreover, at least in the contexts of surrogacy and marital separation agreements, very often neither of these two reasons will justify enforcement, so that women will be protected from the contracts' oppressive consequences without losing full contractual agency. Importantly, such protection would be the result of contractual logic itself rather than special relief from, or limitation of, such logic. ${ }^{19}$

17 See id. at 1284.

${ }^{18}$ See id. at 1269. "Institutional policy" refers to the value of, and the effects of nonenforceability on, a given institution-such as the institution of mortgage guarantees.

${ }^{19}$ See id. at 1280. 
In the specific case of mortgage guarantee contracts, however, Hadfield argues that enforcement should be the norm. ${ }^{20}$ She proposes the general rule that reliance damages will be paid in the event of breach unless the bank either failed to explain the details of the agreement itself or failed to require that the spouse receive independent legal counsel. ${ }^{21}$ Of course, under the current regime, the bank relies upon the guarantee only because of its background knowledge that the legal system will enforce the contract in the event of default: Either the bank will receive a presumably profitable rate of interest in the case of compliance, or a house that is worth more than the amount of the loan in the case of default. But under a reliance-damage rule, the bank may receive less than this in the case of default. If one assumes that such mortgages are more profitable than the next-best alternative use of the bank's funds, then reliance damages, the purpose of which is to put the bank in the position it would have been in absent the contract, would be equivalent to the amount of the unpaid loan plus some lesser rate of profit. To the extent that this would be the consequence of switching from expectation to reliance damages, then such a switch could have the effect of endangering the availability and institution of such mortgages. Banks might charge a higher rate of interest to make up the difference or might be more reluctant to enter into the mortgages. Thus, there could be some measure of conflict between the two reasons for enforcement that Hadfield proposes as better justified rationales than "she chose"-reliance and institutional policy-and it would then be necessary to determine the priority between them.

Turning to more general considerations, I wonder to what extent Hadfield's alternative theory of contract enforcement based on the notion of expressive rather than instrumental choice actually does or should rely upon the incommensurability thesis at all. For Elizabeth Anderson and Richard Pildes, the plurality and incommensurability of values are an essential part of their general critique of rational

${ }^{20}$ See id. at 1267.

${ }^{21}$ This, incidentally, would be an example of a situation where the contract is entered into for expressive rather than instrumental reasons, but with full knowledge of risk allocation. As such, I think Hadfield's argument that the normal justification for enforcement does not work is incomplete. Why does the expressive reason for entering the contract trump knowledge of its consequences? See supra text accompanying note 15 . 
choice theory. ${ }^{22}$ But in the way, and for the purposes, that Hadfield employs the notion of expressive choice, it is unclear to me if expressive choice depends on the incommensurability of values or is rather to be understood more simply as a different frame of reference for entering certain types of contracts as a descriptive matter. Thus, a person might enter a surrogacy contract for expressive reasons rather than instrumental ones, whether or not incommensurable values are involved. Moreover, one reason that Hadfield might prefer the latter account and limit her reliance on Anderson and Pildes-and hence the general incommensurability thesis-is that unlike them, she is not (as I understand it) challenging the general coherence of rational choice's conception of rationality, but rather its monopoly. Hadfield does not wish to undermine the general institution of commercial contracts, which she states rests on the rational choice model, but rather seeks to distinguish such contracts from expressive ones in terms of the appropriate and justified reasons for enforcement. By contrast, although Anderson and Pildes's primary goal is to undermine the claims of rational choice as an appropriate model of rationality in political and collective decisionmaking, they do so by using the incommensurability thesis to undermine its general coherencein all contexts, including private, individual decisionmaking. ${ }^{23}$ It is not, for them, solely a problem of imperialism.

Finally, I wonder whether the solution that Hadfield offers to the dilemma of choice is the only possible solution and, if not, why it might be thought preferable. The dilemma itself, once again, is that either women are held to their contractual commitments in constrained choice situations such as the three highlighted in her article, or they are granted special protection from the normal rules of contractual enforcement, in which case they lose their full contractual agency. The structure of Hadfield's solution is to replace the ad hoc nature of nonenforcement (which gives rise to a sense of "special protection") with a new, general theory of expressive contracts containing its own distinctive rationales for enforceability. Expressive contracts are contracts that may or may not be enforceable depending on whether either of the two rationales for enforcement is satisfied.

${ }^{22}$ See Pildes \& Anderson, supra note 11, at 2143 (" $[\mathrm{T}]$ his claim that values are irreducibly plural undermines the vision of rationality lying at the heart of social choice theory.").

${ }^{23}$ See id. ("The central claim of this Part is that social choice theory's conception of rationality fails to acknowledge the fundamental plurality of values at stake in private and public choices." (emphasis added)). 
Nonenforcement under the expressive theory does not entail loss of agency. Another solution, however, which adopts the same basic structure, would be to deny that expressive contracts are contracts at all in situations where enforcement is not justified. This similarly would preserve contractual agency, because the contract formation rules pertaining to expressive contracts would (like Hadfield's enforcement rationales) also be general ones, part of the new contractual logic rather than an ad hoc departure from, or limitation of, it. Moreover, this second solution would fit reasonably comfortably within traditional consideration doctrine on the basis that promises made for expressive reasons are not exchanges. Is anything gained by insisting that expressive contracts are contracts even where they are not enforceable, so long as their nonenforceability is based on a general contractual logic rather than on a "special" exemption from that logic?

\section{II}

In his rich and carefully argued article, Professor Strudler defends the counterintuitive proposition that lawful (nonfraudulent) lying by lawyers about their clients' reservation prices in certain common circumstances does not violate any relevant moral principles, so that there is no necessary conflict between law and morality on this issue. Strudler employs the argument for the moral permissibility of such lying to illustrate his broader thesis that normative deliberation among a set of options very often involves a judgment about incommensurable values-in particular, morally acceptable and morally tainted values-rather than a calculation of which option provides more of a single, shared value. ${ }^{24}$ Moreover, Strudler argues, his analysis of the lying example, and of the type of normative deliberation it involves, indicates that reasoning about incommensurables is a much more ordinary and common part of moral deliberation than much of the legal literature suggests. ${ }^{25}$

My sense is that the article's most general and ambitious claimabout the frequency of incommensurables in normative deliberation-turns, to a significant extent, on the particular conception of incommensurability employed by Strudler, or (more precisely given the distinction discussed at the beginning of this Comment) on the fact that his conception is more one of incommensurability than in-

\footnotetext{
${ }^{24}$ See Strudler, supra note 9, at 1534-35

${ }^{25}$ See id. at 1564-66.
} 
comparability. In making this observation, I do not at all intend to suggest that Strudler's conception is idiosyncratic, ${ }^{26}$ but merely to reiterate that incommensurability is different from incomparability and to point out that since the former is almost certainly more common than the latter, which of the two is employed may well help to explain the perceived frequency of incommensurable options in moral deliberation.

For Strudler-as for a number of others involved in debates on the subject ${ }^{27}$-if two normative options are incommensurable, it does not follow that one option cannot be morally better than the other. ${ }^{28}$ It means, rather, that they do not share some single desirable property or kind of value, so that determining which option is the morally better one is not a process of comparing which has more of this property or value. ${ }^{29}$ But this emphatically is not to say that other ways to compare incommensurable options do not exist. In particular, Strudler contends, where one of the options contains morally acceptable value and the other contains morally tainted value, as in the case of a less wealthy society without the institution of slavery and a wealthier society with slavery, the first option is morally better and provides the only justified choice. ${ }^{30}$ It is the morally better option, but not because it has more of a particular shared property or value than the other. ${ }^{31}$ In this way, there can be a morally right answer when choosing between incommensurable options.

As Strudler acknowledges, ${ }^{32}$ this conception of incommensurability is different from that employed by Joseph Raz, for example, in which reason runs out among incommensurable options and there is

${ }^{26}$ Indeed, Strudler has persuaded me in conversation that the conception of incommensurability he employs is in line with the dominant one (or ones) in the philosophical literature on the subject. See, e.g., HENRY S. RICHARDSON, PRACTICAL REASONING ABOUT FINAL ENDS 103-05 (1994) (arguing that value commensurability obtains only when we can compare goods in terms of the degree to which they share some desirable characteristic as a basis for making a choice among them); MICHAEL STOCKER, PLURAL AND CONFLICTING VALUES 214-18 (1990) (stating that incommensurability obtains where there is no common unit of value in terms of which items can be measured, but this does prevent justified choice among incommensurables based on the absolute, "concrete" merits of the chosen alternative).

${ }^{27}$ See, e.g., sources cited supra note 26.

${ }^{23}$ See Strudler, supra note 9 , at 1531-37.

${ }^{29}$ See id.

So See id. at $1535-36$.

${ }^{31}$ See id.

${ }^{32}$ See id. at 1533 n.12 (contrasting his own "cognitive" account of incommensurability with the "voluntarist" view of Raz). 
no one choice that is uniquely justified. ${ }^{33}$ For Raz, we instead choose among incommensurables as an act of will or for expressive reasons. Such choice may indeed have its own rationality, but one that is agent-centered rather than determined by the options themselves. ${ }^{34}$ This second conception, which is really a conception of incomparability, implies that incommensurable options cannot be rationally compared at all-their relative worth cannot be assessed. As we have seen, for Strudler, they can be compared, but not quantitatively; that is, not on the basis that one has more of a shared property than another. $^{35}$ Thus, slavery can be compared with nonslavery and found wanting morally because it violates deontological norms. ${ }^{36}$ A slightly different way of putting the same point is that, for Strudler, normative deliberation among options is either about "moreness" or else it is incommensurable. For Raz, by contrast, two options are not necessarily incommensurable where normative deliberation between them is not about moreness; rather, incommensurability exists where there is no basis for justified choice at all. ${ }^{37}$ Unlike the choice between tea and coffee, ${ }^{38}$ Raz would not deem the choice between slavery and nonslavery an incommensurable one.

I do not belabor this point because I think it is a necessary-or even a useful-enterprise to decide which conception of incommensurability best deserves the label, or to defend the use of one rather than the other. Indeed, it is precisely the great merit of acknowledging the distinction between incommensurability and incomparability that such questions to some extent can be avoided. Nonetheless, the two conceptions have different implications for the issues of the fre-

3s See RAZ, supra note 2, at 322 ("A and B are incommensurate if it is neither true that one is better than the other nor true that they are of equal value."). I believe that Elizabeth Anderson also employs this conception of incommensurability, or something close to it. See Pildes \& Anderson, supra note 11, at 2158-59 ("When the sources of competing values at stake in political choices are very diverse, individuals sometimes cannot judge either that one option is better than another or that the options are equal. These are situations of radical incommensurability.... [I]n the face of radically incommensurable options, that a choice has been made cannot always be taken to mean that a value judgment has also been reached about the relative worth of the two options.").

${ }^{4}$ See RAZ, supra note 2, at 388 ("Choice between incommensurables is undetermined by reason. When we choose we choose for a reason. Whichever option we adopt we do so because of the factors which make it attractive.").

${ }^{35}$ See Strudler, supra note 9, at 1531-37.

${ }^{36}$ See id. at 1535-36.

${ }^{37}$ See RAZ, supra note 2 , at 322.

${ }^{33}$ See id. at 328-29 (explaining that coffee and tea are insignificant incommensurables). 
quency of incommensurable options and the role of will in deciding among them, and making this explicit helps us to understand how and why the positions differ. Specifically, Strudler's use of a "cognitive" conception of incommensurability explains why deliberation among incommensurables is so normal or routine; many normative judgments involve us in nonquantitative reasoning among options, whatever we think about the further question of whether the choice that we make can be rationally justified. Moreover, I suspect this also explains much of Strudler's disagreement with Cass Sunstein about how central the practice of expressive choice is with respect to incommensurable options. ${ }^{39}$ For Strudler, the possibility of a uniquely justified choice is not eliminated by acknowledging that one is choosing among incommensurables. ${ }^{40}$ But, to the extent that Sunstein employs the Razian conception of incommensurability (that is, incomparability), this possibility is eliminated, so that the actual choice made can only be justified on the basis of will or expression, rather than the balance of moral reasons. ${ }^{41}$

The conclusion of Strudler's substantive discussion of the issue of lying by lawyers about reservation prices is that, contrary to the standard view, such lying is morally permissible, at least under certain fairly common circumstances, and its fruits are therefore not morally tainted. ${ }^{42}$ In a sense, this conclusion is a little curious given Strudler's larger ends in his article, because it seems to follow that the choice between lying and truth-telling is not a choice between incommensurables after all, and yet the example is intended to illustrate how frequent and mundane choices among incommensurables are. But putting this unimportant point aside, his conclusion sets up a conflict between two morally untainted courses of action-obtaining more money for one's client by lying about reservation prices and obtaining less by not lying - and yet at this critical point, Professor Strudler's analysis appears to provide little guidance on the issue of how we should approach the task of resolving it.

${ }^{39}$ Professor Strudler argues that it is melodramatic of Professor Sunstein to insist that choice among incommensurables is always an expressive or existentialist choice. See Strudler, supra note 9, at 1564-66.

${ }^{40}$ See id. at 1531-37.

1 See Cass R. Sunstein, Free Markets and Social Justice 91-92 (1997) (explaining the grounds for endorsing the expressive function of law); Cass R. Sunstein, Incommensurability and Valuation in Law, 92 MICH. L. REv. 779, 805-08 (1994) (discussing the relationship between Sunstein's and Raz's understanding of incommensurability).

${ }^{42}$ See Strudler, supra note 9, at 1561-64. 
It is certainly both true and very helpful to have so clearly demonstrated that many decisions we face involve options containing different kinds of value so that moral deliberation among them cannot be a process of "moreness." Further, if some of these options contain morally tainted value, we can exclude them from further consideration-perhaps, if we are lucky, we can exclude all options except one. Strudler's account, however, does not seem to tell us very much in situations, such as the lying example on which he focuses, where both options (or more than one option) have passed muster under the various deontological tests he posits. From a moral perspective, should we lie if this will give our client more money? Is the deliberation now purely commensurable? Strudler's analysis tells us that we can rationally choose between options when one is morally excluded, but does not provide obvious guidance when one is not.

Moreover, in his analysis, options appear to be either morally acceptable or not. But surely there are cases, including arguably the lying case, where options are more or less acceptable. Even if lying is morally permissible, isn't it always, or usually, still better not to lie? If so, how then do we decide between the two options with their corresponding dollar figures?

Turning finally to a more technical point, toward the beginning of his article, Strudler states that commensurability does not imply consequentialism and that there is no inconsistency in a Kantian being a commensurabilist. ${ }^{43}$ By the end of his article, I found myself wondering whether he believes that incommensurability implies commitment to deontology. The considerations of autonomy and fairness that Professor Strudler employs in the lying context to determine whether an option is morally acceptable are exclusively deontological. But he does not address the issue of whether there might be other, nondeontological considerations in contexts other than the lying one. Must morally acceptable options be considered in purely deontological terms? In other words, does Strudler think a deontological framework is necessary for his general incommensurability thesis, or does he, rather, independently believe in this framework and as a result not consider alternatives? I do not think accepting consequentialist notions of morality is necessarily inconsistent with his general thesis that morally valuable options, including those justified on consequentialist grounds, are incommensurable with morally unacceptable ones. If an option is morally unacceptable, it does not

\footnotetext{
${ }^{43}$ See id. at 1532 n.8.
} 
appear to matter on what particular ground this is so. If lying is morally wrong on consequentialist grounds, I see nothing to prevent one from arguing that it is still an unacceptable option and therefore cannot be compared with a morally acceptable one. 